\title{
COAGULATION PROFILE IN MYELOPROLIFERATIVE NEOPLASMS.
}

1. MBBS, FCPS

Assistant Professor Haematology

FMH College of Medicine and

Dentistry, Lahore.

2. MBBS, FCPS

Professor Haematology

Shaikh Zayed Medical Complex, Lahore.

3. MBBS, M.Phil

Assistant Professor Haematology Rahber Medical and Dental College Lahore.

4. MBBS, FCPS

Assistant Professor Haematology Sahiwal Medical College, Sahiwal.

5. MBBS, FCPS Haematology Assistant Professor Pathology

M.Islam Medical and Dental College Gujrawala.

6. MBBS, FCPS

Senior Registrar Neurology

Mayo Hospital Lahore.

Correspondence Address:

Dr. Sadia Taj

House No. 261 Block A,

Canal View Society, Lahore.

sadia.adnan11@gmail.com

Article received on:

29/06/2019

Accepted for publication:

$11 / 10 / 2019$

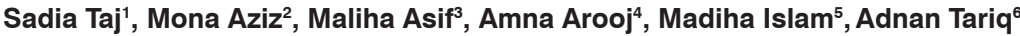

ABSTRACT... Objectives: Evaluation of coagulation profile in patients with Myeloproliferative Neoplasms. Study Design: Cross sectional survey. Setting: Department of Haematology, Shaikh Zayed Hospital, Lahore. Period: 10-03-2015 to 09-03-2016. Materials \& Methods: A total of 55 patients of myeloproliferative neoplasms (Chronic Myeloid leukaemia, Polycythemia vera, Essential thrombocytosis and Primary Myelofibrosis) were studied over 1 year period. Patients of $>15 \mathrm{yrs}$ and both the genders were included. Patients already on anticoagulation and liver disease were excluded. All patients underwent screening of PT, APTT and D-dimer. PT and APTT was measured by KC4 Amelung coagulometer and D-Dimer by Latex Kit 60X. Results: Twenty four of 55 cases (43.64\%) of myeloproliferative neoplasms had elevated Prothrombin time. Activated partial thromboplastin time was elevated in 18 of 55 (32.73\%) cases and D-Dimer was elevated in 11 of $55(20 \%)$ cases. Conclusion: CML is statistically the most spreading form of MPN and ET is least common form in comparison with other MPNs. Thrombohaemorrhagic complications significantly affect the morbidity and mortality of MPN patients which can be assessed by coagulation studies. Timely diagnosis of these prothrombotic/haemorrhagic states can decrease the morbidity in these patients
\end{abstract}

Key words: Coagulation Profile, Myeloproliferative Neoplasms, Thrombosis.

Article Citation: Taj S, Aziz M, Asif M, Arooj A, Islam M, Tariq A. Coagulation profile in myeloproliferative Neoplasms. Professional Med J 2020; 27(5):944-949. DOI: 10.29309/TPMJ/2020.27.05.3864

\section{INTRODUCTION}

Myeloproliferative Neoplasms (MPN) refer to clonal disorder of hematopoiesis that lead to an increase in number of one or more mature blood cell progeny. ${ }^{1}$ The $\mathrm{WHO}$ includes 4 disorders in Myeloproliferative Neoplasms which include Chronic myeloid leukaemia, Polycythemia vera, Essential thrombocytosis and Primary myelofibrosis. $^{2}$

Thrombosis is a leading complication in Myeloproliferative Neoplasms particularly in Polycythemia vera and Essential thrombocytosis. Thrombotic incidence ranges from $12-39 \%$ in Polycythemia vera, and from 11-25\% in Essential thrombocytosis. ${ }^{3}$ While in Primary myelofibrosis and Chronic myeloid leukaemia it is $7.2 \%{ }^{4}$ and $6.1 \% 5$ respectively.

Hemorrhagic diathesis is more rare, mostly effects patients with a very high plt count 1000 to $2000 \times 10^{9} / 1^{6}$
Patients of MPN are in a hypercoagulable state even in the absence of frank thrombotic events. This is proven by the increased levels of plasma biomarkers of haemostatic system activation. ${ }^{7}$ Studies in patients with venous thrombosis with or without Myeloproliferative Neoplasms showed that treatment with anticoagulants decreases the rate of recurrent thromboses which support the use of anticoagulants in patients with Myeloproliferative Neoplasms. ${ }^{8}$ Elevated D-dimer levels measured 1 month after discontinuation of oral anticoagulants identify patients at high risk of recurrent thrombotic events, $16.6 \%$ Patients with elevated D-dimer level experienced recurrent venous thromboembolic events. ${ }^{9}$

There has been no local study on the coagulation profile of Myeloproliferative Neoplasms and due to racial difference we expect different results in our population. In our local practices we do not evaluate the coagulation profile until the patients come with the thrombotic and hemorrhagic 
complications, thus signifying the importance of studying coagulation profile.

\section{MATERIAL \& METHODS}

This was a Cross sectional survey of 1 year conducted in Department of Haematology, Shaikh Zayed Hospital, Lahore. 55 patients of MPNs with age >15yr and both the genders presenting to hematology outdoor were included. Patients of MPNs including Chronic Myeloid leukaemia with BCR-ABL1 translocation, patients of Polycythemia vera, Essential thrombocytosis and Primary Myelofibrosis with or without Janus Kinase 2 mutation were recruited.

Patients with concomitant liver disease, renal disease and patients taking anticoagulation therapy were excluded.

Sample was collected with D-dimer test Latex kit 60X to measure D-dimers, and Prothrombin time(PT), International Normalized Ratio(INR) and Activated partial thromboplastin time (APTT) with KC4 Amelung coagulometer.

Quantitative variable like age was presented as Mean \pm SD. Qualitative variables like gender and values of abnormal coagulation profile was presented in the form of frequency and percentages.

\section{RESULTS}

A total of 55 cases were enrolled to evaluate the coagulation profile in patients with Myeloproliferative Neoplasms.

Patients were grouped according to types of MPN (Table-I)
Patients were distributed according to age (Figure-1) showing that $45.45 \%$ of 55 cases were between $15-40$ years of age, $23.64 \%$ were between $41-60$ years of age, while $30.91 \%$ were $>60$ years of age, mean \pm SD was calculated as $48.16+16.07$ years.

Gender distribution has been presented in figure No.2 which shows $49 \%$ patients were males and $51 \%$ were females.

Coagulation profile in patients with myeloproliferative neoplasms was recorded. Prothrombin time was elevated in $32.73 \%$ cases, Activated partial thromboplastin in $43.64 \%$ cases. Both PT and APTT in $25.45 \%$ cases and D-Dimer in $20 \%$ cases (Table-II).

Prothrombin Time, Activated Thromboplastin Time and D-Dimer level according to type of myeloproliferative neoplasms are shown in (Table-III to V).

Among 19 cases of CML Prothrombin time was elevated in $36.84 \%$ cases, Activated partial thromboplastin in $47.37 \%$ and D-Dimer in $31.58 \%$ cases. Among 18 cases of PV Prothrombin time was elevated in $33.33 \%$ cases, Activated partial thromboplastin in $38.89 \%$ and D-Dimer in $11.11 \%$ cases. Among 11 cases of PMF Prothrombin time was elevated in $36.36 \%$ cases, Activated partial thromboplastin in 54.54\% and D-Dimer in 27.27\% cases. Among 7 cases of ET Prothrombin time was elevated in $14.29 \%$ case, Activated partial thromboplastin in $28.57 \%$ cases and D-Dimer in none. (Table-VI)

\begin{tabular}{|l|c|c|}
\hline \multicolumn{1}{|c|}{ Group } & No. of Patients & $\%$ \\
\hline CML & 19 & 34.55 \\
\hline PV & 18 & 32.73 \\
\hline PMF & 11 & 20.0 \\
\hline ET & 07 & 12.72 \\
\hline Total & 55 & 100 \\
\hline
\end{tabular}

Table-I. Patients according to type of myeloproliferative neoplasms $(n=55)$ 


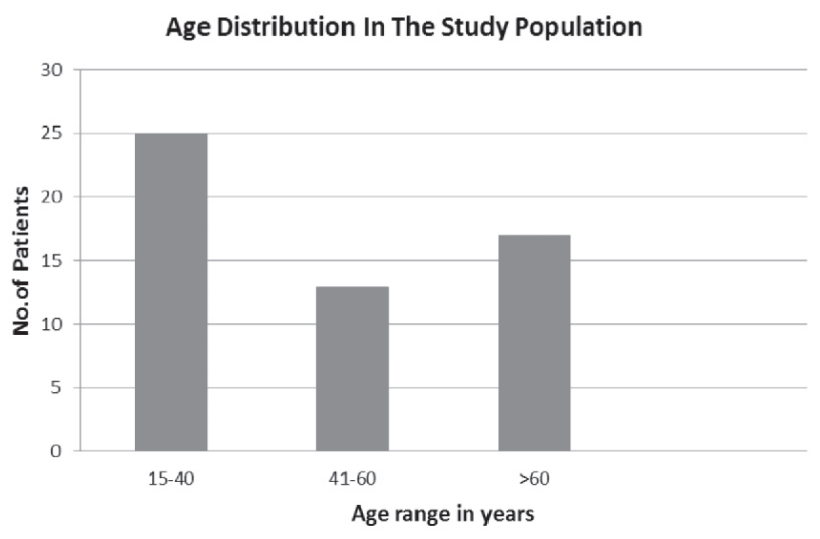

Figure-1. Age distribution in study population

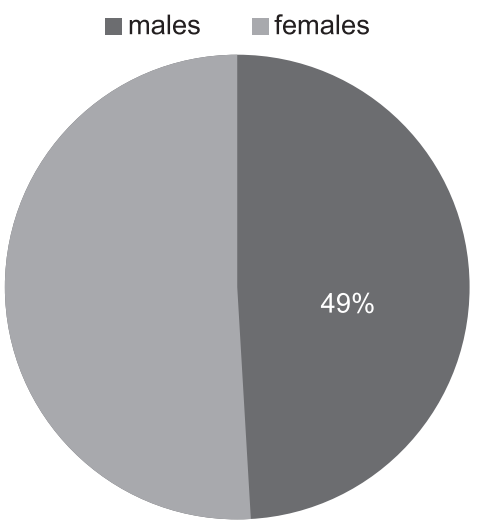

Figure-2. Gender distribution in study population

No. of Patients

\begin{tabular}{|c|c|}
\hline 18 & $\%$ \\
\hline 24 & 32.73 \\
\hline 14 & 43.64 \\
\hline 11 & 25.45 \\
\hline
\end{tabular}

Table-II. Coagulation profile in patients with myeloproliferative neoplasms $(n=55)$

\begin{tabular}{|c|c|c|c|c|c|c|}
\hline \multirow[t]{2}{*}{ Group } & \multicolumn{2}{|c|}{$\begin{array}{l}\text { Elevated } \\
\text { PT }\end{array}$} & \multicolumn{2}{|c|}{$\begin{array}{c}\text { Normal } \\
\text { PT }\end{array}$} & \multicolumn{2}{|c|}{ Total } \\
\hline & $\mathbf{N}$ & $\%$ & $\mathbf{N}$ & $\%$ & $\mathbf{N}$ & $\%$ \\
\hline PV & 6 & 33.33 & 12 & 66.67 & 18 & 100 \\
\hline PMF & 4 & 36.36 & 7 & 63.63 & 11 & 100 \\
\hline ET & 1 & 14.29 & 6 & 85.71 & 07 & 100 \\
\hline
\end{tabular}

Table-III. Prothrombin time according to the type of myeloproliferative neoplasms $(\mathrm{N}=55)$

\begin{tabular}{|c|c|c|c|c|c|c|}
\hline \multirow{2}{*}{ Group } & \multicolumn{2}{|c|}{$\begin{array}{c}\text { Elevated } \\
\text { APTT }\end{array}$} & \multicolumn{2}{|c|}{ Normal APTT } & \multicolumn{2}{|c|}{ Total } \\
\hline & $\mathbf{N}$ & $\%$ & $\mathbf{N}$ & $\%$ & $\mathbf{N}$ & $\%$ \\
\hline PV & 7 & 38.89 & 11 & 61.11 & 18 & 100 \\
\hline PMF & 6 & 54.54 & 5 & 45.45 & 11 & 100 \\
\hline ET & 2 & 28.57 & 5 & 71.43 & 07 & 100 \\
\hline
\end{tabular}

\begin{tabular}{|c|c|c|c|c|c|c|}
\hline \multirow{2}{*}{ Group } & \multicolumn{2}{|c|}{$\begin{array}{l}\text { Elevated } \\
\text { D-Dimer }\end{array}$} & \multicolumn{2}{|c|}{$\begin{array}{l}\text { Normal } \\
\text { D-Dimer }\end{array}$} & \multicolumn{2}{|c|}{ Total } \\
\hline & $\mathbf{N}$ & $\%$ & $\mathbf{N}$ & $\%$ & $\mathbf{N}$ & $\%$ \\
\hline PV & 2 & 11.11 & 16 & 88.89 & 18 & 100 \\
\hline PMF & 3 & 27.27 & 8 & 72.73 & 11 & 100 \\
\hline Total & 11 & 20 & 44 & 80 & 55 & 100 \\
\hline
\end{tabular}




\begin{tabular}{|c|c|c|c|c|c|c|c|}
\hline \multirow[t]{2}{*}{ Group } & \multirow{2}{*}{$\begin{array}{c}\text { TOTAL } \\
\text { Cases } \\
\mathbf{N}\end{array}$} & \multicolumn{2}{|c|}{$\begin{array}{c}\text { PT } \\
\text { Elevated }\end{array}$} & \multicolumn{2}{|c|}{$\begin{array}{c}\text { APTT } \\
\text { Elevated }\end{array}$} & \multicolumn{2}{|c|}{ D-DIMER Elevated } \\
\hline & & $\mathbf{N}$ & $\%$ & $\mathbf{N}$ & $\%$ & $\mathbf{N}$ & $\%$ \\
\hline PV & 18 & 6 & 33.33 & 7 & 38.89 & 2 & 11.11 \\
\hline PMF & 11 & 4 & 36.36 & 6 & 54.54 & 3 & 27.27 \\
\hline Total & 55 & 18 & 32.73 & 24 & 43.64 & 11 & 20 \\
\hline
\end{tabular}

\section{DISCUSSION}

Myeloproliferative Neoplasms are a heterogenous group of disorders characterized by cellular proliferation of 1 or more haematologic cell lines in the peripheral blood, distinct from acute leukemia . The clinical course of myeloproliferative neoplasms (MPN) is frequently complicated by thrombotic and haemorrhagic events. Microparticles (MPs) are membrane fragments that range in size from 0.1 to 1 micrometer, and are considered as biomarkers responsible for prothrombotic state in many clinical diseases.

The study comprised of 55 cases, of which CML was found to be most common disorder and ET was the least common disorder diagnosed in this study.

Most of our cases $45.45 \%$ were young between $15-40$ years of age $23.64 \%$ were between $41-60$ years of age, while $30.91 \%$ were $>60$ years of age Mean \pm SD was calculated as $48.16 \pm 16.07$ years. Our cohort did not show any significant gender predominance. These results were compared with a study done by Smith et al..$^{10}$ in UK which showed an older age of presentation ( $>60$ years) of MPN in UK which is different from our population, may be due to racial or geographic differences. However, gender distribution did not show any significant difference.

Among all cases of myeloproliferative neoplasms, Prothrombin time was elevated in 18 (32.73\%) cases, Activated partial thromboplastin in 24 (43.64\%), both PT and APTT were elevated in $14(25.45 \%)$ and D-Dimer in 11 (20\%). A study by Simonovic et al. ${ }^{11}$ in 2007 , showed that $40 \%$ of patients with myeloproliferative neoplasm has elevated PT and $27 \%$ patients had elevated APTT, these findings are also comparable with the findings recorded in our study. Gadomska et al. ${ }^{12}$ in his study found PT and APTT with MPN fell within reference ranges although median APTT was significantly higher among patients with MPN, and D-Dimer was also significantly higher.

In present study, we noted PT was elevated in $32.73 \%$ patients, this has been most prominent in the group with CML, where about 7 of 19 (36.84\%) patients were found with elevated PT. Simonovic et al. ${ }^{11}$ found largest percentage of patients with elevated prothrombin time in the group with $\mathrm{CML}$ (about 52\%).

APTT was elevated in more than one third of the cases $43.64 \%$ with MPN, the highest number of the cases with elevated APTT was found in the group with PMF, where 6 of $11(54.54 \%)$ patients were found with elevated APTT, and it has statistically been much more in comparison with $\mathrm{CML}$ and PV. Simonovic et al. ${ }^{11}$ also found largest percentage of patients with elevated APTT in the group with PMF (about 50\%).

D-Dimer level were elevated in $20 \%$ patients with MPN, this has been most prominent in group with CML, where 6 of 19(31.58\%) patients were found with elevated D-Dimer level. Gadomska et al. ${ }^{12}$ found D-Dimer level was significantly higher in all subgroups with MPNs in his study. The presence of D-Dimer is a proof of secondary activation of fibrinolytic system.

A meta-analysis done by Sekhar et $\mathrm{al}^{13}$, concluded Splanchnic vein thrombosis (SVT) occurs more frequently in MPN than in the general population, 
but enigma of SVT occurring prior to an overt neoplastic state is an important phenomenon in patients with underlying MPN who present with SVT. ${ }^{14}$

A meta-analysis of studies of patients with idiopathic VTE was done by Bruinstroop et al. ${ }^{9}$ to assess the predictive value of D-Dimer level in patients with history of venous thrombosis that showed $16.6 \%$ patients with elevated D-dimer level, experienced recurrent venous thromboembolic events. In our local practices we do not evaluate the coagulation profile in MPN patients until the patients come with the thrombotic and hemorrhagic complications, thus further signifying the importance of studying coagulation profile in MPN.

The data regarding findings of coagulation profile with underlying Myeloproliferative neoplasms is scarse. However, our findings may be considered as primary and some other trials should be done so that our results may be validated and used in future.

\section{CONCLUSION}

We concluded that $\mathrm{CML}$ is statistically the most spreading form of MPN and ET is least common form in comparison with other MPNs. Thrombohaemorrhagic complications significantly affect the morbidity and mortality of MPN patients which can be assessed by coagulation studies. Prompt diagnosis of these prothrombotic/haemorrhagic states can decrease the complications in these patients. Advance understanding of molecular events that lead to MPN may provide appropriate targeted therapy for the production of bifunctional effects that are capable to control malignant process as well as to prevent coagulopathy.

\section{Copyright@ 11 Oct, 2020.}

\section{REFERENCES}

1. Campbell PJ, Green AR. Myeloproliferative neoplasms. In: Hoffbrand AV, Catovsky D, Tuddenham EGD, Green AR, editors. Postgraduate Haematology. $6^{\text {th }}$ ed. UK: Blackwell Publishing Ltd; 2011. P.686.

2. Radich J. The molecular biology of myeloproliferative disorders. Cancer Cell. 2010; 18(1):7-8.
3. Falanga $A$, Marehetti $M$. Thrombotic disease in myeloproliferative neoplasm. ASH Education Book; 2012(1): 571-81.

4. Blom JW, Vanderschoot JPM, Oostinder MJ, Osanto S, Vandermeer FJM, Rosendaal FR. Incidence of venous thrombosis in a large cohort of 66329 cancer patients: Results of a record linkage study. JTH. 2006; 4(3): 529-35.

5. Barbui T, Carobbio A, Cervantes F, Vannucchi AM, et al. Thrombosis in primary myelofibrosis: Incidence and risk factors. Blood. 2012; 115(4): 778-82.

6. McMullin MF, Harrison CN , Ali S, Cargo C, Chen F, Ewing $\mathrm{J}$ et al, $\mathrm{A}$ guideline for the diagnosis and management of polycythaemia vera. BJH. 2019 Jan; 184(2): 176-191.

7. Parashar $\mathrm{Y}$, Kushwaha R, Kumar A, Agarwal K, Singh US, Jain M, et al. Haemostatic profile in patients of myeloproliferative neoplasms-A Tertiary Care Centre Experience. Journal of Clinical Diagnostic Research. 2016 Nov; 10(11): EC01-EC04.

8. Hoekstra J, Bresser EL, Smalberg JH, Spaander MCW, Leebeek FWG, Janssen HLA. Long-Term follow up of patients with portal vein thrombosis and myeloproliferative neoplasms. JTH. 2011; 9(11): 2208-14.

9. Bruinstroop E, Klok FA, Vanderee MA, Oosterwijk $\mathrm{FL}$, Huisman MV. Elevated d-dimer levels predict recurrence in patients with idiopathic venous thromboembolism: A meta analysis. JTH. 2009; 7(4): 611-18.

10. Smith A, Howell D, Patmore R, Jack A, Roman E. Incidence of haematological malignancy by subtype: A report from the Haematological Malignancy Research Network. British Journal of Cancer. 2011; 105:1684-1692.

11. Simonovic E, Golubovic LM, Milenovic M, Mladenovic $\mathrm{M}$, Colic V. Basic biochemical parameter significant in diagnosis of myeloproliferative disease. Medicine and Biology. 2007; 14(2): 82-87.

12. Gadomska G, Rosc D, Stankowska K, Boinska J, Ruszkowska CiastekB, Wieczor R. Selected parameters of hemostasis in patients with myeloproliferative neoplasms. Blood coagulation and fibrinolysis. July 2014; 25(5):464-70.

13. Sekhar M, McVinnie K, Burroughs AK. Splanchnic vein thrombosis in myeloproliferative neoplasms. $\mathrm{Br} J$ Haematol 2013; 162:730. 
14. Kouides PA, Bennett JM. Morphology and classification of the myelodysplastic syndromes and their pathologic variants. Semin Hematol 1996; 33:95.

\begin{tabular}{|c|c|c|c|}
\hline \multicolumn{4}{|c|}{ AUTHORSHIP AND CONTRIBUTION DECLARATION } \\
\hline Sr. \# & Author(s) Full Name & Contribution to the paper & Author(s) Signature \\
\hline 1 & Sadia Taj & 1st Author & Qa div \\
\hline 2 & Mona Aziz & 2nd Author & \\
\hline 3 & Maliha Asif & 3rd Author & $\begin{array}{l}\text { Utha Asif } \\
\text { bmrko }\end{array}$ \\
\hline 4 & Amna Arooj & 4th Author & Nmdiha \\
\hline 5 & Madiha Islam & 5th Author & $d$ \\
\hline 6 & Adnan Tariq & 6th Author & \\
\hline
\end{tabular}

